\title{
Globe
}

Revue internationale d'études québécoises

\section{De circulation et de renouvellement}

\section{Daniel Chartier}

Volume 6, numéro 2, 2003

La circulation des discours

URI : https://id.erudit.org/iderudit/1000813ar

DOI : https://doi.org/10.7202/1000813ar

Aller au sommaire du numéro

Éditeur(s)

Globe, Revue internationale d'études québécoises

ISSN

1481-5869 (imprimé)

1923-8231 (numérique)

Découvrir la revue

Citer ce document

Chartier, D. (2003). De circulation et de renouvellement. Globe, 6(2), 11-12. https://doi.org/10.7202/1000813ar d'utilisation que vous pouvez consulter en ligne.

https://apropos.erudit.org/fr/usagers/politique-dutilisation/ 


\section{Présentation \\ De circulation et de renouvellement}

Dans ce douzième numéro de la revue, le dernier sous ma direction, Michel Lacroix a réuni des auteurs qui réfléchissent sur les particularités de la circulation des discours au Québec, tant dans leur médiation par les questions de langue et de publicité que dans leurs rapports avec l'idéologie, la diversité culturelle, la perception des conflits étrangers et le discours économique de la Révolution tranquille.

En ouverture, Magali Deleuze analyse la perception de la guerre d'Algérie dans les journaux québécois, en posant le problème en termes de méthodologie des sciences humaines; suit un article de Chantal Ringuet qui examine les spécificités des œuvres littéraires écrites par les écrivaines d'Europe de l'Est qui ont émigré au Québec au cours des dernières années. En étudiant le discours publicitaire de l'Hydro-Québec, Dominique Perron constate combien la publicité de la société d'État a joué un rôle, au début des années 1970, dans l'établissement d'une symbolique nationaliste québécoise. Danielle Forget et Boriana Panayotova remarquent dans leur article que les manuels scolaires ont fait une place à la diversité culturelle, mais que l'articulation des discours historique et pluraliste s'inscrit sur le mode de la tension. Enfin, Gabrielle Saint-Yves interprète une querelle linguistique du tournant du $\mathrm{xx}^{\mathrm{e}}$ siècle entre Firmin Paris et Louis Fréchette comme la manifestation d'un conflit social plus complexe, qui témoigne du débat de société de l'époque.

Dans la section "études libres", nous publions un article de JeanFélix Chénier consacré à la pensée politique du philosophe Charles Taylor. Suivent les recensions et les parutions récentes en études québécoises.

Les prochains numéros relèveront de la responsabilité de Michel Lacroix et d'Éric Trudel, qui ont accepté de prendre ma relève et qui deviennent les directeurs de la revue pour un mandat de trois ans. Tous deux ont été, dans le passé, secrétaire à la rédaction. Karine Cellard 
devient maintenant secrétaire à la rédaction, après un mandat de cinq ans au comité d'administration. Les deux nouveaux directeurs, professeurs au Collège universitaire Bard (Éric Trudel) et à l'Université du Québec à Trois-Rivières (Michel Lacroix), poursuivront donc leur collaboration à la revue, toujours au Département d'études littéraires de l'Université du Québec à Montréal et en partenariat avec le Centre de recherche interuniversitaire sur la littérature et la culture québécoises (CRILC).

Après avoir fondé la revue Globe et en avoir assuré la direction pendant six ans, j'en cède en toute confiance la destinée à une équipe qui saura poursuivre l'objectif de publier une revue pluraliste et pluridisciplinaire qui favorise la participation des chercheurs étrangers d'une cinquantaine de pays au discours scientifique sur le Québec. Une fois encore, je tiens à remercier la centaine d'universitaires qui ont généreusement collaboré au succès de la revue depuis 1998 ; je pense particulièrement à Stephan Gervais, Brigitte Faivre-Duboz, Karine Cellard et Michel Lacroix, ainsi qu'à tous les membres présents et passés des comités d'administration, de rédaction et du comité scientifique. Pour ma part, je resterai avec fidélité lié à la revue à titre de membre de son comité de rédaction.

Si nos lecteurs lisent avec intérêt la revue, ils ne voient pas nécessairement le travail collectif d'édition qui anime les équipes de la revue depuis sa fondation. Dès le départ, nous avons défendu avec fermeté des modes égalitaires et équitables de gestion, tout en inscrivant dans nos structures de fonctionnement les principes auxquels nous croyons : nécessité d'équilibre entre les hommes et les femmes, entre les générations de chercheurs, entre le Québec et l'étranger, entre les disciplines universitaires, entre les positions politiques, entre les institutions universitaires, entre Montréal et les régions et, surtout, entre les positions critiques sur le Québec.

Je souhaite donc aux nouveaux directeurs le même plaisir que j'ai eu à défendre ces principes avec la ferme conviction que seule leur application peut permettre l'émergence d'un discours pluraliste et équilibré sur le Québec, sa culture et sa société.

Daniel Chartier

Université du Québec à Montréal 